\title{
AVALIAÇÃO DA APLICABILIDADE DA EDUCAÇÃO AMBIENTAL CRÍTICA NAS PRINCIPAIS TRILHAS DA SERRA DE ARATANHA EM PACATUBA (CE)
}

\author{
Jefferson de Sousa Brito ${ }^{1}$ \\ Gheysa Mara Carneiro Paiva²
}

Resumo: A Educação Ambiental Crítica - EAC questiona a relação serviçal da natureza em relação ao homem. O município de Pacatuba/CE apresenta grande potencial turístico, sendo as trilhas ecológicas um dos principais atrativos. Foi avaliado, a partir de sete questionários aplicados à guias/condutores e visita em campo, como as trilhas ecológicas são utilizadas para EAC. Como resultado foi identificado que as trilhas apresentam um caráter cênico, com alto grau de dificuldade de uso, em detrimento a viabilidade de uso na EAC. Os guias possuem limitada formação teórica e reduzida capacidade de delinear uma visão crítica dos elementos naturais de forma a alterar a cultura dos usuários.

Palavras-chave: Educação Ambiental Crítica; Trilhas Ecológicas; Formação de Guias.

Abstract: Critical Environmental Education - EAC questions the servant relationship of nature in relation to man. The municipality of Pacatuba / CE has great tourist potential, and the ecological trails one of the main attractions. From seven questionnaires applied to guides / drivers and field visit, we evaluated how the ecological trails are used for EAC. As a result it was identified that trails have a scenic character, with high degree of difficulty of use, to the detriment of the viability of use in the EAC. The guides have limited theoretical background and reduced ability to delineate a critical view of the natural elements in order to alter the users' culture.

Keywords: Critical Environmental Education; Ecological Trails; Guide Formation. 


\section{Introdução}

Entre os desafios ambientais para a sociedade contemporânea, o que se destaca como expoente, a internalização da compreensão que o modelo de bem-estar a partir do consumo ilimitado é incompatível com o ideal que a sociedade poderá se perpetuar como grupo dominante na Terra é inviável, pois afronta os limites da natureza. A visão antropocêntrica, em relação ao meio ambiente, subjuga a fauna, flora, fenômenos e ciclos naturais a servirem como fonte de satisfação, na maioria das vezes, a um grupo de indivíduos de uma única geração ou casta, assim negligenciando a própria garantia de um ambiente equilibrado para seus descendentes.

Um dos instrumentos que se consolidou na busca pela modificação do status quo do domínio irracional do homem sobre a natureza e permitiu a sensibilização para o cenário de interdependência homem-natureza foi a Educação Ambiental - EA. Historicamente, a questão da EA ganhou maturidade no ano de 1977 na Conferência Intergovernamental de Tbilisi onde surgiu seu marco como recomendação mundial (RAMOS, 2001, p. 204).

A Educação Ambiental, como instrumento jurídico, no Brasil surgiu de forma consolidada com a evolução da legislação ambiental. A Constituição Brasileira de 1988 trouxe pela primeira vez um capítulo dedicado ao meio ambiente e em seu artigo 225, parágrafo $1^{\circ}$, inciso $\mathrm{VI}$, declarou que deverá ocorrer a promoção da Educação Ambiental em todos os níveis de ensino e a conscientização pública para a preservação do meio ambiente. A Política Nacional de Meio Ambiente - PNMA, Lei Federal 6.938/81, trouxe em seu artigo $2^{\circ}$, inciso X, a EA como um dos seus princípios. Finalmente, a Política Nacional de Educação Ambiental - PNEA, Lei Federal oㅜ 9.795/99, sacramentou esse instrumento ao cotidiano político e social brasileiro.

$A$ inserção da EA na sociedade ocorreu a partir de canais distintos previstos na PNEA: a formal e a não formal. A educação formal é aquela aplicada na educação escolar, em instituições públicas e privadas, englobando educação básica, superior, especial, profissional e de jovens e adultos. A educação não formal é aquela constituída pelas ações e práticas educativas voltadas à sensibilização da coletividade sobre questões ambientais e a sua organização e participação na defesa da qualidade do meio ambiente fora do ambiente escolar (BRASIL,1999).

No entanto, é necessário compreender que as ações de Educação Ambiental não deveriam se exaurir em si próprias, mas permitir que se mude o comportamento social (GIL; BOMFIM, 2017, p. 7). Notoriamente, as ações de EA foram pontuais e buscaram sanar problemas de forma imediatista, o que caracteriza a Educação Ambiental dita conservadora, ou seja, aquela que não questiona a ordem social estabelecida com base nas suas origens históricas e, assim sem reverberar em uma mudança de consciência ambiental do indivíduo como um todo (LOUREIRO, 2006, p.138).

Como alternativa, a limitação do alcance das mudanças de consciência dos indivíduos em relação à importância do meio ambiente, a 
Educação Ambiental Crítica - EAC buscou solidificar as ações ambientais na realidade e rotina dos indivíduos, pois foi fundamentada no pensamento crítico, aplicado à educação, que permitiu romper a formação e assimilação do conhecimento de forma mecânica e buscou assumir a mediação da construção social de conhecimentos implicados na vida, história e questões urgentes de nosso tempo nas relações sociedade-natureza, além de intervir sobre os problemas e conflitos ambientais, assim criando sujeitos sociais emancipados como sugeriu Paulo Freire um dos fundadores de pensamento crítico (CARVALHO, 2004, p.20). Assim, no educar "ambientalmente" crítico se buscou o sustentável a partir da problematização dos aspectos da vida rotineira composta tanto pelo viés político quanto econômico para apresentar caminhos e padrões societários (PELACANI; MUNIZ; PEREIRA, 2019, p.135).

Entre as ações que buscam trazer a sensibilização ambiental destacam-se as palestras, mutirões de coleta de resíduos sólidos, oficinas de reciclagem e, de forma contundente, a utilização de trilhas ecológicas, e essas tem alcançado enorme significação com o aumento da urbanização e a compreensão que a fuga do asfalto das cidades é uma forma de lazer rica (SIQUEIRA, 2004 apud PADOAN; JÚNIOR, 2014, p.7).

As trilhas ecológicas são de acordo com Silva et al. (2012, p.708) percursos demarcados em áreas naturais que propiciam a interpretação ambiental, o resgate histórico - cultural e os fenômenos locais. A prática de trilhas deve ir além da contemplação ou da prática esportiva, mas permitir a reflexão e sensibilização do visitante levando-o a observar, sentir, experimentar, questionar, racionalizar e descobrir (SILVEIRA, 2009 apud ALMADA; BERNADES, 2015, p.4). Quando executadas de forma bem planejadas e devidamente mantidas as trilhas protegem o meio dos impactos da própria utilização (COSTA, 2005 apud ALMADA; BERNADES, 2015, p.4).

A Serra de Aratanha em Pacatuba - Ceará possui uma grande variedade de trilhas ecológicas que se distribuem em várias localidades do município como nos distritos de Monguba, Quandú e Sede (PAIVA, 2015, p.61). A preocupação com o mau uso dos recursos naturais fez com o Governo do Estado do Ceará criasse no dia 05 de junho de 1998 a Unidade de Conservação Área de Proteção Ambiental (APA) da Serra de Aratanha, por meio do Decreto Estadual no 24.959, com o objetivo de proteger e conservar a serra em virtude da sua importância ambiental e do grande valor ecológico.

Assim, o objetivo desse trabalho, de forma inovadora, é avaliar como as atuais práticas, formação de condutores e infraestrutura das mais representativas trilhas ecológicas utilizadas na Serra de Aratanha se adequam a utilização pela Educação Ambiental Crítica. Como objetivos secundários são a apresentação da caracterização social dos guias e a descrição das trilhas. Finalmente, apresentar um conjunto de ações que poderão ser implantadas para potencializar os resultados positivos e minimizar os negativos.

Como subsídios para a compreensão desse trabalho serão abordados os elementos relativos à caracterização socioambiental do município de Pacatuba de forma a ilustrar o potencial da Educação Ambiental. A relevância 
das trilhas ecológicas para EA, além das suas limitações e potencias enquanto instrumento. Por outro lado, será apresentada a discussão sobre a definição de Educação Ambiental Crítica como contraponto a Educação Ambiental Conservadora. E finalmente, as conclusões e sugestões que caracterizam e permeiam a aplicabilidade da EAC nas principais trilhas existentes em Pacatuba.

\section{Referencial Teórico}

\section{Caracterização socioambiental de Pacatuba}

O município de Pacatuba (Figura 1) está inserido nas bacias Metropolitanas. Essas bacias localizam-se na porção nordeste do Estado do Ceará, limitadas ao sul pela bacia do rio Banabuiú, a leste pela bacia do rio Jaguaribe, a oeste pela bacia do rio Curu, e ao norte, pelo Oceano Atlântico. Os municípios sobre a área de influência além de Pacatuba são Fortaleza, Caucaia, São Gonçalo do Amarante, Pindoretama, Cascavel, Beberibe, Maracanaú, Maranguape, Itaitinga, Guaiúba, Horizonte, Pacajus, Chorozinho, Redenção, Barreira, Acarape, Palmácia, Guaramiranga, Mulungu, Pacoti, Baturité, Aracoiaba, Aratuba, Capistrano, Itapiúna, Choró, Ibaretama e Itapiuna (CEARÁ, 2009, p.17).

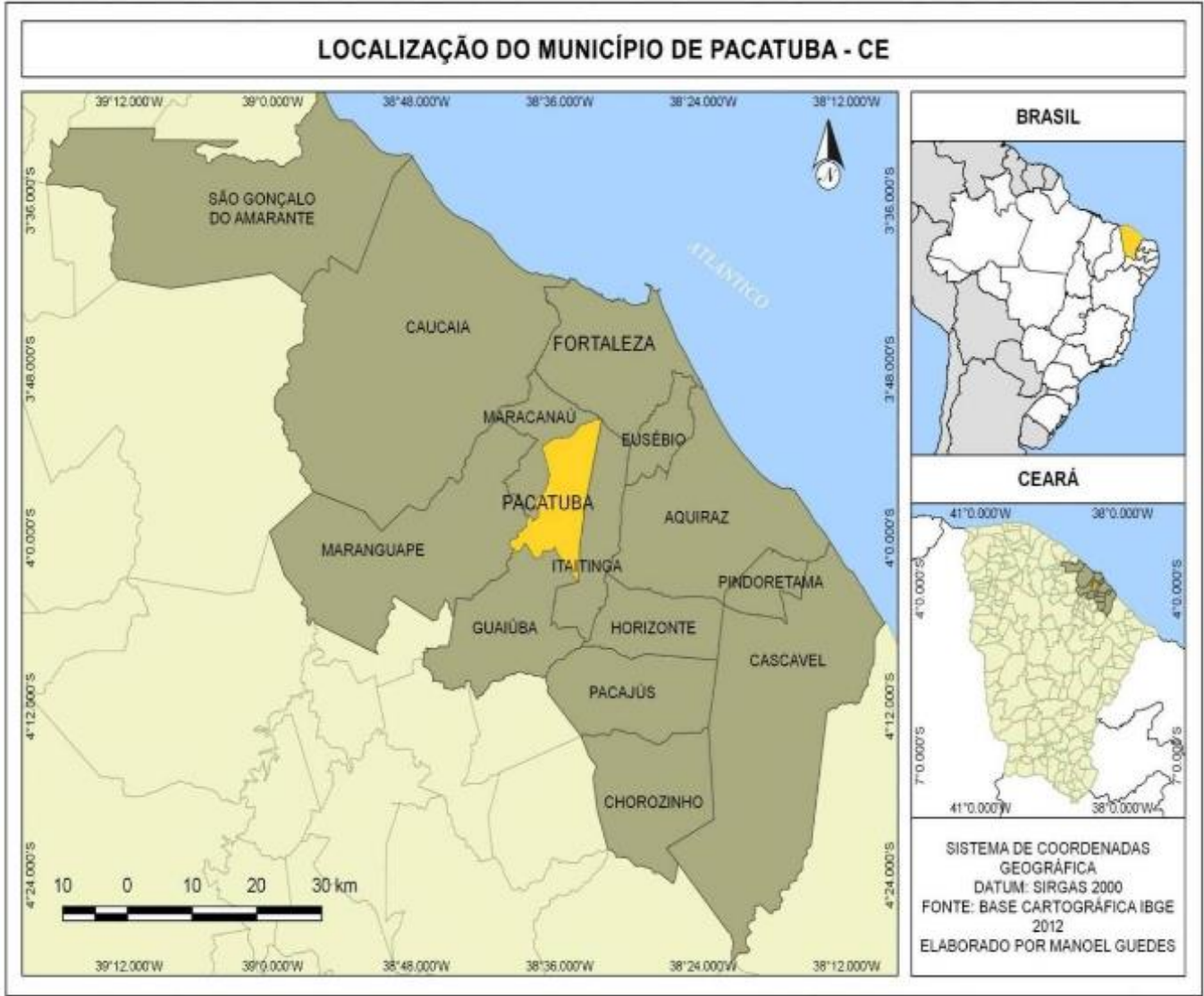

Figura 1: Localização do Município de Pacatuba.

Fonte: Guedes (2014, apud PAIVA, 2015). 
As principais bacias que compõem possuem uma área total de 15.085 $\mathrm{km}^{2}$, cobrindo $10 \%$ da área do estado do Ceará. As principais são: dos rios Choró (200km), Pacoti (112,5km), São Gonçalo, Pirangi (177,5km), Ceará e Cocó. Ao todo são dezesseis as sub-bacias dessa região (CEARÁ, 2009, p.17).

As bacias Metropolitanas apresentam altitudes médias de $0 \mathrm{~m}$ (litoral) a pouco menos de $900 \mathrm{~m}$ (Serra de Baturité). O solo é cristalino no alto e médio curso e com formações de Barreiras e cordões de dunas mais próximas ao litoral. A média anual pluviométrica varia de $800 \mathrm{~mm}$ a $1400 \mathrm{~mm}$. As temperaturas variam de entre $26 \stackrel{\circ}{\circ}$ e $28 \stackrel{\circ}{\circ}$ em um clima caracterizado como tropical quente subúmido. As vegetações predominantes são a do Complexo Vegetacional da Zona Litorânea e a Caatinga Arbustiva Densa, além das Florestas Subperenifólia Tropical Pluvio-Nebular (Mata Úmida) e a Floresta Subperenifólia Tropical Pluvial (CEARÁ, 2009, p.18).

Os recursos hídricos superficiais caracterizam-se por apresentarem um volume hidrográfico de pequeno porte e de pouca representatividade, no entanto, importantes por banharem áreas urbanas. Possui 693 reservatórios, destes, 512 apresentam área superior a cinco ha. A bacia apresenta 18 reservatórios importantes, porém apenas 15 apresentam capacidade superior a 10 milhões de $\mathrm{m}^{3}$. Entre esses se destaca o sistema de reserva para abastecimento da região metropolitana conhecida como Pacoti/Riachão, porém é interligado a outros açudes como Aracoiaba e o Pacajus (CEARÁ, 2009, p.24).

A água subterrânea é intensamente utilizada na região, havendo o cadastro de 17.969 pontos d'água em 2006. As águas subterrâneas são formadas em dois sistemas aquíferos: rochas sedimentares (porosos e aluviais) e os das rochas cristalinas (fissurais) (CEARÁ, 2009, p.26).

A ocupação do solo é de grande variedade nas bacias Metropolitanas, havendo municípios que são estritamente urbanos e outros rurais. Essa ocupação tão eclética decorre da inserção da Região Metropolitana de Fortaleza dentro da bacia juntamente com municípios tipicamente interioranos. Assim, ao se tentar qualificar os tipos de poluição que os corpos hídricos sofrem são tanto difusas quanto as pontuais. Essa exposição pode ser bem observada pelo simples fato que há ao longo da bacia municípios que até 2008 apresentavam $0 \%$ de esgotamento sanitário e apenas $50 \%$ de abastecimento público (CEARÁ, 2009, p.72).

O município de Pacatuba apresenta uma base econômica variada com a presença dos três setores econômicos. No setor primário se destacam a produção agrícola com a presença de lavouras temporárias (cana de açúcar, feijão, mandioca, melancia, melão e milho) e lavouras permanentes (banana, castanha de caju, coco da baia, laranja, mamão, manga e maracujá). A extração vegetal é representada pelos subprodutos da carnaúba. A pecuária se destaca pela criação de bovinos, equinos, suínos, caprinos, ovinos e galináceos (PAIVA, 2015, p. 27).

Revbea, São Paulo, V. 15, № 3: 18-35, 2020. 
Destaca-se no extrativismo a mineração, extração de rochas ornamentais, rochas para cantaria, brita, placas para fachada e usos diversos na construção civil (Figuras 2A e 2B), notadamente no distrito de Monguba (BRASIL, 1998, p.7).

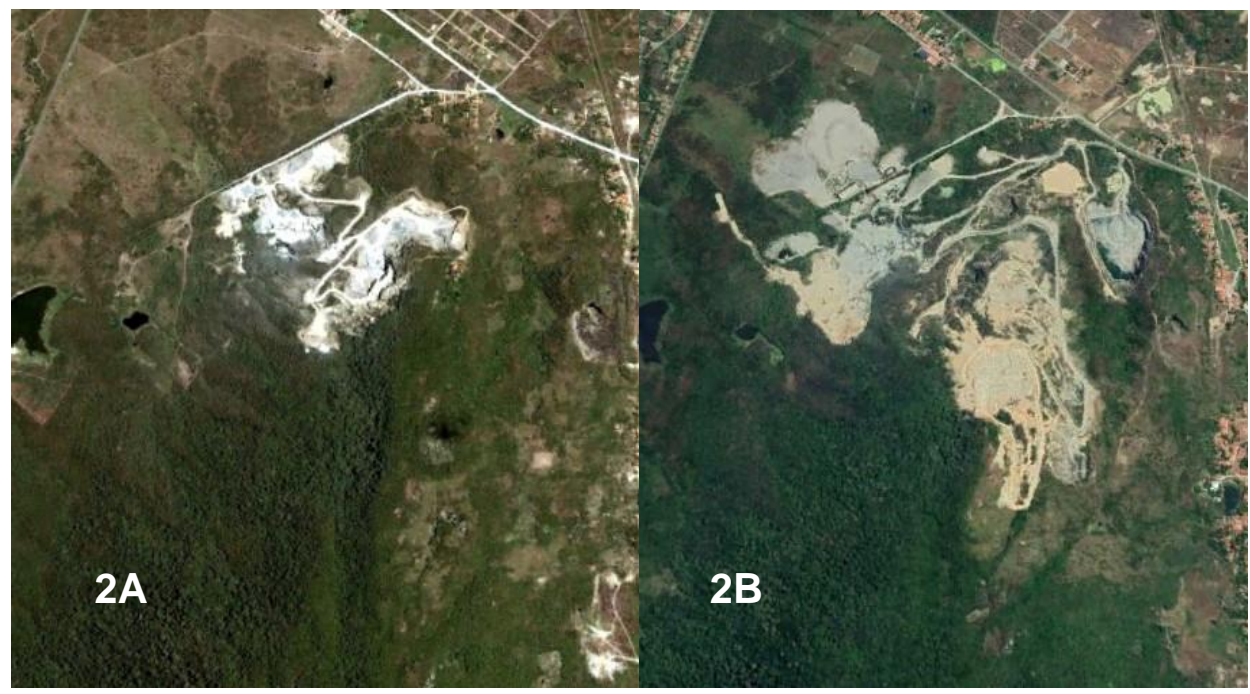

Figura 2: Evolução visual da ocupação pela mineração no morro da Monguba localizada entre Pacatuba e Maracanaú. (2a) Vista da área em 2004; (2b) Vista da área em 2019.

Fonte: Imagens modificadas do Google Earth.

No setor secundário Pacatuba apresenta um pujante parque industrial em decorrência da expansão dos conjuntos indústrias, notadamente o do município de Maracanaú, e das indústrias que buscaram alternativas locacionais para se instalarem na região metropolitana de Fortaleza. O parque industrial é composto por empresas têxteis e de confecção, de bebidas, embalagens e outras (PAIVA, 2015, p. 40).

A ocupação do espaço territorial de Pacatuba também apresenta uma forte alteração do solo para a instalação de loteamentos e conjuntos habitacionais como alternativa a elevação dos custos nos municípios de Fortaleza e Maracanaú.

Finalmente, no setor terciário a atividade turística é representada pelo turismo religioso, histórico, ecoturismo e de aventura. $\mathrm{Na}$ prestação de serviços e comércio destacam-se as atividades de transporte e armazenamento, além dos setores varejistas e atacadistas (PAIVA, 2015, p.41).

A população do Município de Pacatuba foi estimada em 2017 em 82.824 habitantes (BRASIL, 2017). A área de estudo apresenta a peculiaridade de possuir uma população indígena da etnia Pitaguary distribuída entre os municípios de Maracanaú e Pacatuba (distrito de Monguba). 


\section{Educação Ambiental Crítica aplicada a trilhas ecológicas}

A prática, hodierna, da utilização das trilhas ecológicas é de compreendê-las como um instrumento eficaz na sensibilização para transmissão de informações ambientais de acordo com Santos et al. (2011, apud PADOAN; JÚNIOR, 2014, p.7) e Zanin (2006 apud SANTOS; FLORES; ZANIN, 2011, p.192). Essa transferência deve afetar não somente comportamentos imediatos, mas, principalmente, as crenças e atitudes dos visitantes (KIMKER, 2002 apud KRUG et al., 2015, p.1). A interação com a natureza, de acordo com pesquisa feita com alunos universitários e revisão da literatura por Rosa \& Profice (2018), apresenta uma relação positiva para formação de crenças ambientais mais fortes.

Contudo, a prática da EA esbarra no que Guimarães (2004) e, já citado, Loureiro (2006) chamam de Educação Ambiental Conservadora, onde a transferência de conhecimento ocorre de forma a perpetuar a compreensão que os elementos naturais presentes nas trilhas têm seu valor a partir da visão antropocêntrica de exploração. Essa visão antropocêntrica é potencializada pelos efeitos deletérios do distanciamento das questões sociais (AVANZI, 2004).

Assim, a EAC busca contornar a visão utilitarista da natureza e questionar a relação homem-natureza por um viés integrativo e de interdependência de todos os elementos. Essa construção de acordo com Guimarães (2004) baseou-se em três pilares que referendaram a Teoria Crítica aplicada a EA: leitura crítica desenvolvida por Paulo Freire; espaço conceituado por Milton Santos; e, o complexo, que é o diálogo da parte com o todo e, assim resultando em algo diferente, de acordo com Edgar Morin. Logo, a EA Crítica se contrapõe a EA Conservadora ao questionar os interesses das classes dominantes e a lógica do capital (GUIMARÄES, 2004, p.26).

Como instrumento de aplicação da teoria chamada por Loureiro (2004, p.65) de "Educação Ambiental Transformadora" as trilhas ecológicas, atualmente, apresentam um enorme vácuo diante do potencial delas. A própria produção acadêmica ao buscar materializar o uso de trilhas, muitas vezes, se subsidia de informações e resultados voltados para a visão antropocêntrica e conservadora. Assim, essa produção é alheia à incorporação da "transformação" da perspectiva do indivíduo além daquele instante, ou seja, no tecido social.

Silva et al. (2012) avaliou uma trilha como prática ambiental no turismo rural e concluiu que as discussões e ações buscavam a manutenção e o conhecimento dos elementos próprios da trilha. Santos, Flores e Zanin (2011) avaliaram um projeto voltado a atividades lúdico-pedagógicas utilizando trilhas, no entanto despertando a conscientização de forma limitada aos temas da preservação dos recursos naturais, conservação de áreas naturais e coleta seletiva. 
Krug et al. (2015) sugeriram um modelo interpretativo para uma trilha em um campus com o objetivo de aplicar diferentes estratégias educacionais e comunicação ambiental focados na observação da biodiversidade da Mata Atlântica. Assim, após realizarem o diagnóstico da trilha apresentaram uma sugestão de dez (10) temas a serem abordados, além do respectivo conteúdo de cada tema. Contudo, a maior parte das abordagens era de cunho conservador ao não apresentar como a interação do homem altera o meio, na maioria das vezes, de forma deletéria. Padoan e Júnior (2014) apesar de buscarem a construção de uma trilha interpretativa na Serra do Catete (Ouro Preto/MG) que deveria subsidiar a introdução de um contexto histórico, cultural e econômico, se limitou a construir um modelo de caracterização ecológica da área.

Essa dificuldade em encontrar trabalhos que apliquem a EA Crítica, em sua plenitude, mostra que o tema é um desafio a sua aplicação.

\section{Material e Métodos}

Nos procedimentos metodológicos foi utilizada a pesquisa qualitativa e descritiva com entrevistas semiestruturadas direcionadas aos condutores de trilhas, indicados pela Secretaria de Turismo de Pacatuba, além de entrevistas com técnicos da própria prefeitura de Pacatuba, revisão bibliográfica, observação direta, pesquisa de campo e levantamento fotográfico.

Foram aplicados sete (7) questionários, do universo de cerca de 30 guias cadastrados, durante o mês de julho de 2019, elaborados com objetivo de identificar e avaliar entre os guias as principais trilhas, o grau de dificuldade de uso e a capacidade das mesmas de transferir de forma crítica informações ambientais e culturais com a abordagem dos seguintes aspectos: 1) Diferencial das trilhas; 2) Pontos positivos e fragilidades; 3) Conservação do meio ambiente; 4) Repasse de informações sobre condutas responsáveis e sustentabilidade aos visitantes; 5) Ações para evitar a desordem ambiental nas trilhas. O questionário foi construído com onze (11) questões dos tipos binárias, discursivas e de avaliação escalonada em cinco (5) níveis, entre muito baixa e muito alta.

Dessa forma a aplicação dos questionários aos guias, além da pesquisa de campo e a entrevista com os técnicos da prefeitura, foi imprescindível para confrontar o cenário obtido através da pesquisa teórica com a realidade do local, assim permitindo a construção do cenário de utilização das principais trilhas ecológicas em Pacatuba para a EAC a partir de uma visão holística do tema. 


\section{Trilhas ecológicas de Pacatuba}

O município de Pacatuba se destaca pela diversidade de atividades com o viés para o turismo ecológico. As trilhas, entre as opções, são os elementos basilares, pois permitem 0 acesso a diversas outras atividades como rapel e parapente, além, por si sós, serem de grande apelo turístico. $\mathrm{Na}$ região metropolitana de Fortaleza a qualidade ambiental na Serra de Aratanha se destaca pelo elevado grau de conservação da serra que decorre de alguns fatores peculiares como:

- Presença da Área de Proteção Ambiental da Serra da Aratanha (Figura 3) que cobre os municípios de Pacatuba, Maranguape, Guaiuba e Maracanaú. Em Pacatuba a APA, que possui $6.448,29$ ha no total, possui uma área de $1.751,87$ ha $(22,56 \%$ do total);

- A instalação da Reserva Particular do Patrimônio Natural - RPPN Monte Alegre com 263,17 ha distribuídos entre os municípios de Pacatuba e Maracanaú;

- A luta pela homologação de 1.737 ha reivindicados pela tribo Pitaguary que forma um mosaico com a RPPN Monte Alegre e a APA da Aratanha.

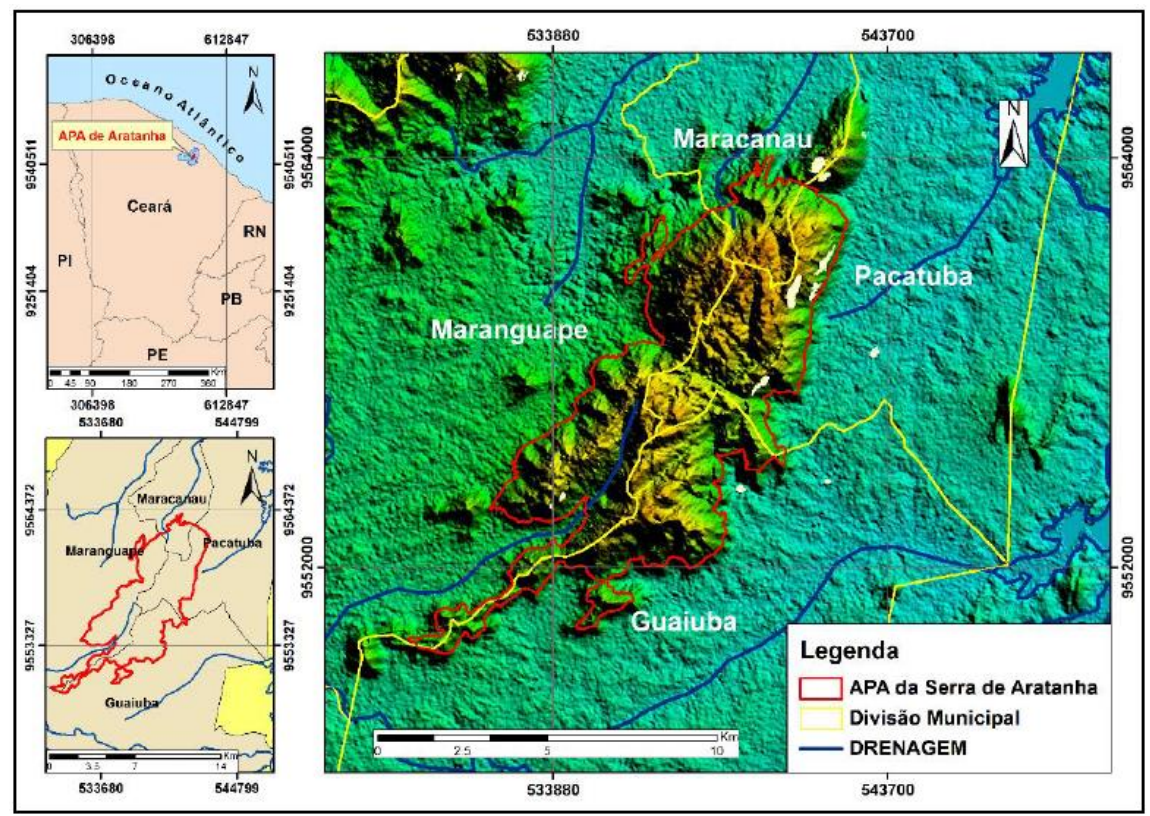

Figura 3: Localização APA da Aratanha.

Fonte: Freire et al (2017). 
De acordo com o Instituto Florestal de São Paulo (2008, p.6) a classificação das trilhas pode ser descrita quanto à forma, a função e o grau de dificuldade (conceito mais relevante para a compreensão deste trabalho). Assim, o grau de dificuldade é apresentado nas seguintes categorias e com as respectivas particularidades:

- Difícil: trilhas com elevada declividade (superior a 20\%), com mais de 10 obstáculos a cada $500 \mathrm{~m}$, com subidas em morros altos; trechos muito longos; requer alguma habilidade na caminhada e bom condicionamento físico;

- Médio: trilhas com declividade moderada (entre 12\% e 20\%), obstáculos que variam de 5 a 9 por cada $500 \mathrm{~m}$, com subidas em morros de porte médio, caminhadas curtas em mata nativa e não requer habilidades;

- Fácil: trilhas com declividade branda (inferior a 12\%), com número reduzido de obstáculos (quatro obstáculos no máximo a cada 500m) e com pouco esforço físico.

A partir das entrevistas foram definidas as principais trilhas para EA. A Trilha do Boaçu (Figuras 4A e 4B) se inicia no Balneário Municipal das Andreas à $77 \mathrm{~m}$ (setenta e sete metros) de altitude e segue em direção ao topo da serra à cerca de $650 \mathrm{~m}$ (seiscentos e cinquenta metros) de atitude.

Apresenta elevado grau de conservação da flora e grandes atrativos culturais. Possui em seu trajeto a casa da "Baronesa", acesso a uma área com destroços de um grande acidente aéreo onde ocorreu a morte de uma grande personagem cearense, o industrial Edson Queiroz, além de outras 136 pessoas, e, finalmente, alcança o açude do Boaçu. A trilha apresenta um nível de dificuldade alto e é concluída, em média, em quatro (4) horas de caminhada. Essas características a tornam do tipo cênico e pouco útil a Educação Ambiental.

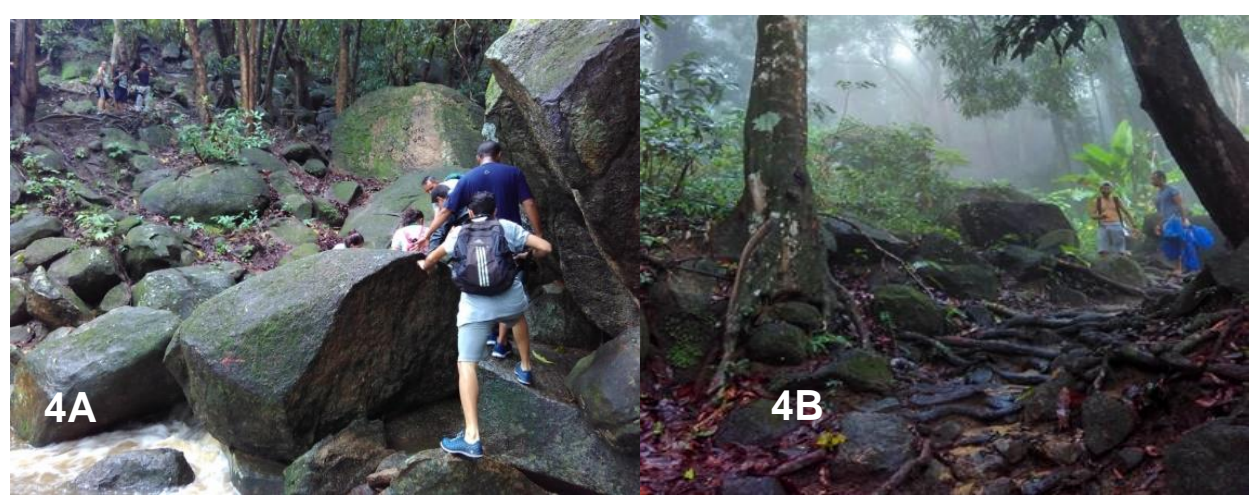

Figura 4: (4a) Início da trilha ainda no Balneário das Andreas; (4b) Presença de raízes e pedras no caminho com elevada declividade.

Fonte: Elaboração própria dos autores. 
A Trilha do CETREFP (Figura 5A e 5B) é integrada a estrada que leva ao Centro de Treinamento Frederico Pontes e apresenta dois trechos com características específicas. No primeiro trecho apresenta médio nível de dificuldade em decorrência da baixa existência de obstáculos (que permite a utilização de veículos) e moderada declividade. No segundo trecho há uma longa distância a ser vencida a pé até alcançar o mirante, ponto final não acessível por veículos. Dura cerca de três (3) horas entre caminhada e deslocamento de carro. Essas características tornam difícil a incorporação de um momento para discussões aprofundadas sobre os elementos observados.

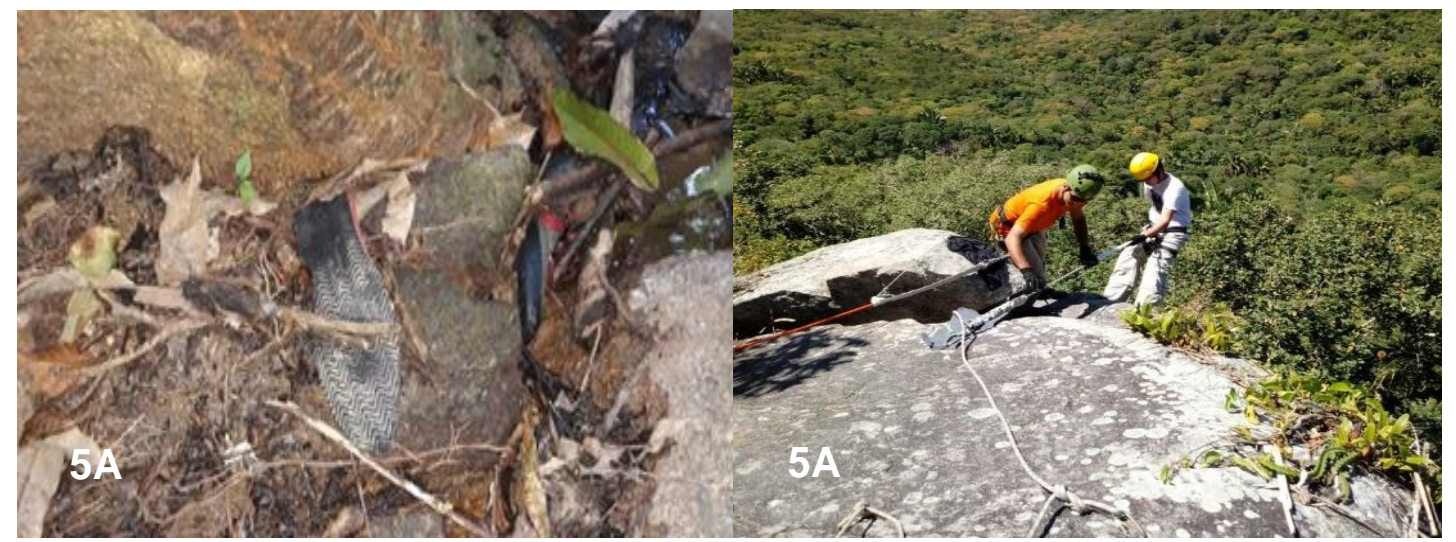

Figura 5: (5a) Restos de tênis observados ao longo da trilha; (5b) Pontos de transição através de rapel. Fonte: Elaboração própria dos autores.

$\mathrm{E}$, finalmente, as Trilhas indígenas (Figuras $6 \mathrm{~A}$ e $6 \mathrm{~B}$ ) que são formadas por três trilhas principais, e algumas secundárias, que permitem acesso à beleza cênica da serra e se diferenciam por ocorrerem tanto em áreas indígenas como guiadas pelos mesmos, assim gerando a possibilidade de se conhecer a cultura deles. A trilha inclui ações específicas como representações de manifestações culturais como as danças e rituais indígenas, além de amenidades como conhecer e saborear os alimentos típicos.

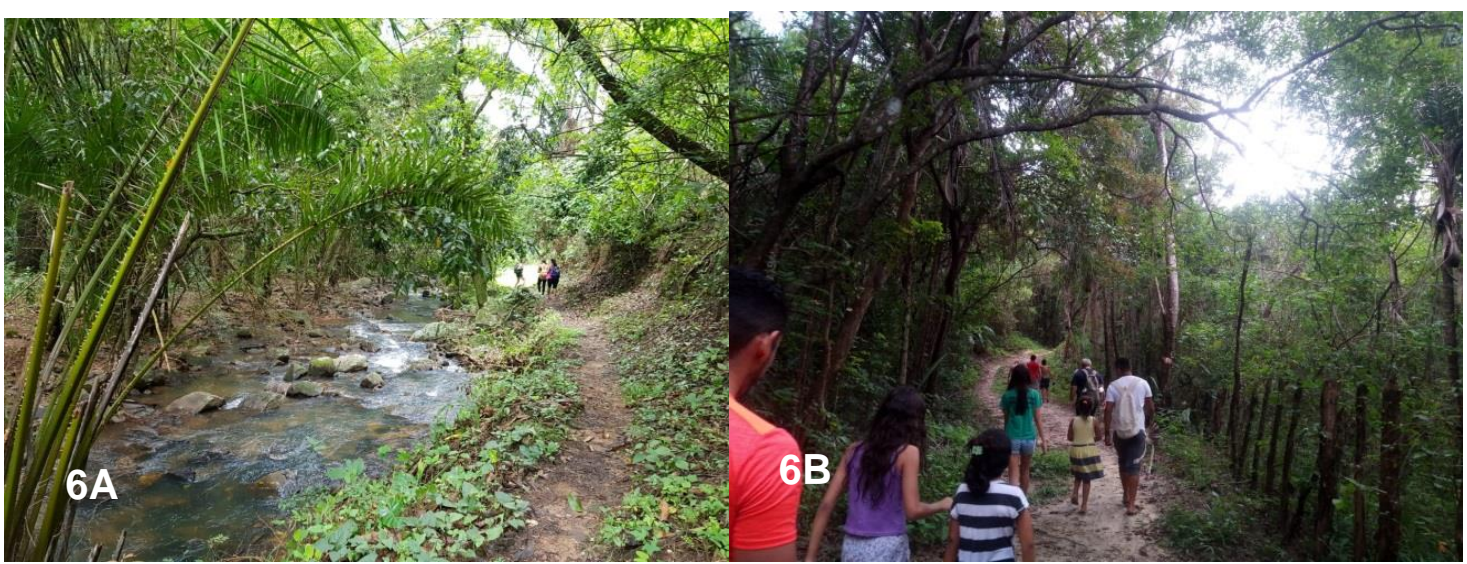

Figura 6: (6a) Corpos lênticos rasos e de baixa velocidade ao longo do percurso; (6b) Trilha usada por crianças. Fonte: Elaboração própria dos autores. 
Contudo, há inúmeras outras trilhas na área indígena que permitem diferentes integrações sociais e culturais, inclusive, permitindo atividades de campi, por exemplo. A diversidade de trilhas permite identificar diferentes níveis de dificuldade, mas as principais apresentam maior facilidade para utilização e um variado conjunto de opções de lazer.

\section{Resultados}

A identificação socioeconômica dos sete (7) guias permitiu destacar que a maioria, cinco (5), apresenta grande experiência prática nas trilhas ao relatarem que há mais de 10 anos realizavam a tarefa. Outra característica é a baixa flexibilidade territorial dos guias, pois todos os guias relataram a prática apenas na Serra de Aratanha e isso corrobora com o fato de todos serem moradores da região.

A motivação das visitas acompanhadas pelos guias, de acordo com a experiência dos condutores, foi prioritariamente a beleza cênica da serra para os usuários. No entanto, para as trilhas que ocorrem em terras indígenas foi possível destacar um interesse pela cultura local.

Sobre trabalhar com a função de guia todos relataram que o maior interesse foi transmitir informações sobre a natureza e a cultura da região. Eles indicaram que as informações transmitidas buscavam transferir ao visitante uma compreensão sobre condutas responsáveis e sustentabilidade.

Nenhum condutor indicou retorno financeiro como motivação para o trabalho. Esse baixo interesse na questão financeira pode ser explicado pelo caráter do baixo profissionalismo da atividade e a visão de ser uma forma de complementar a renda.

Ao avaliar a compreensão sobre temas ligados a gestão ambiental, de forma direcionada a uma avaliação crítica da transferência das informações para além do ambiente da trilha e expandi-lo para o universo fora da Serra de Aratanha, os guias, em sua maioria, apresentaram conhecimentos considerados médios a baixos para os temas abordados de acordo com o Quadro 1 (próxima página).

Contudo, o que podemos observar com esse trabalho, depois da avaliação do preenchimento dos questionários e outras informações repassadas pelos condutores e técnicos da prefeitura, é que o cenário relatado nos questionários se contrapõe com a realidade observada em campo ao se avaliar o conteúdo educacional ministrado durante as trilhas. Assim, a aplicação da auto avaliação não se mostrou a metodologia mais adequada para a análise, pois durante o acompanhamento, por parte dos autores, do preenchimento dos questionários pelos guias, foram necessárias inúmeras intervenções para elucidar os temas apresentados. Assim, uma entrevista semiestruturada teria um potencial de melhor representar o conhecimento dos guias. 
Quadro 1: Síntese de respostas escalonadas sobre a compreensão dos temas relacionados a gestão ambiental. Fonte: Elaboração própria dos autores.

\begin{tabular}{|c|c|c|c|c|c|c|}
\hline \multirow[t]{2}{*}{ Temas } & \multicolumn{5}{|c|}{$\begin{array}{l}\text { Número de } \\
\text { Respostas }\end{array}$} & \multirow{2}{*}{$\begin{array}{l}\text { Avaliação a partir do diálogo pós- } \\
\text { preenchimento }\end{array}$} \\
\hline & 1 & 2 & 3 & 4 & 5 & \\
\hline $\begin{array}{l}\text { Importância de unidades } \\
\text { de conservação }\end{array}$ & & 1 & 4 & 2 & & $\begin{array}{l}\text { O conceito técnico era desconhecido pela maior } \\
\text { parte dos guias, apesar de correlacionarem com } \\
\text { a proteção da natureza era importante. }\end{array}$ \\
\hline Fauna e flora & & 1 & 5 & 1 & & $\begin{array}{l}\text { O domínio se limita a indicar o nome comum de } \\
\text { espécies mais conhecidas na região, no entanto } \\
\text { sem conhecer elementos da ecologia deles. }\end{array}$ \\
\hline $\begin{array}{l}\text { Gestão de resíduos } \\
\text { sólidos }\end{array}$ & & & 4 & 2 & 1 & $\begin{array}{l}\text { Limita-se a compreensão do descarte } \\
\text { inadequado, sem compreender todo o ciclo de } \\
\text { produção (figura 7B). }\end{array}$ \\
\hline Pegada ecológica & 2 & 5 & & & & $\begin{array}{l}\text { Nenhum apresentou compreensão sobre os } \\
\text { efeitos da presença do homem em escala } \\
\text { global. }\end{array}$ \\
\hline $\begin{array}{l}\text { Conhecimentos } \\
\text { relacionados ao meio } \\
\text { cultural e cultura indígena }\end{array}$ & & & & & 1 & $\begin{array}{l}\text { O grupo apresentou maior familiaridade com o } \\
\text { tema em decorrência da origem da maioria dos } \\
\text { próprios guias. }\end{array}$ \\
\hline
\end{tabular}

*Escala: 1- Muito baixa; 2 - Baixa; 3 - Média; 4- Alta; 5 - Muito alta

Durante as visitas às trilhas pode-se observar que a maioria dos condutores de trilhas não apresentou capacitação para oferecer um serviço de maior qualidade aos visitantes, pois possuíam pouco conhecimento transferível sobre a importância do patrimônio ambiental e apresentaram dificuldades para repassar as informações de forma crítica e criteriosa sobre conservação das trilhas (Figura 7A e 7B) e o efeito sobre a fauna e flora. Esse cenário de falta de conhecimento é objeto de várias ações que buscam qualificar os guias como o Manual de Formação GAMBÁ (2012) que além das medidas de segurança e sobrevivência, buscam apresentar um aparato didático amplo sobre conceitos relacionados à gestão ambiental.

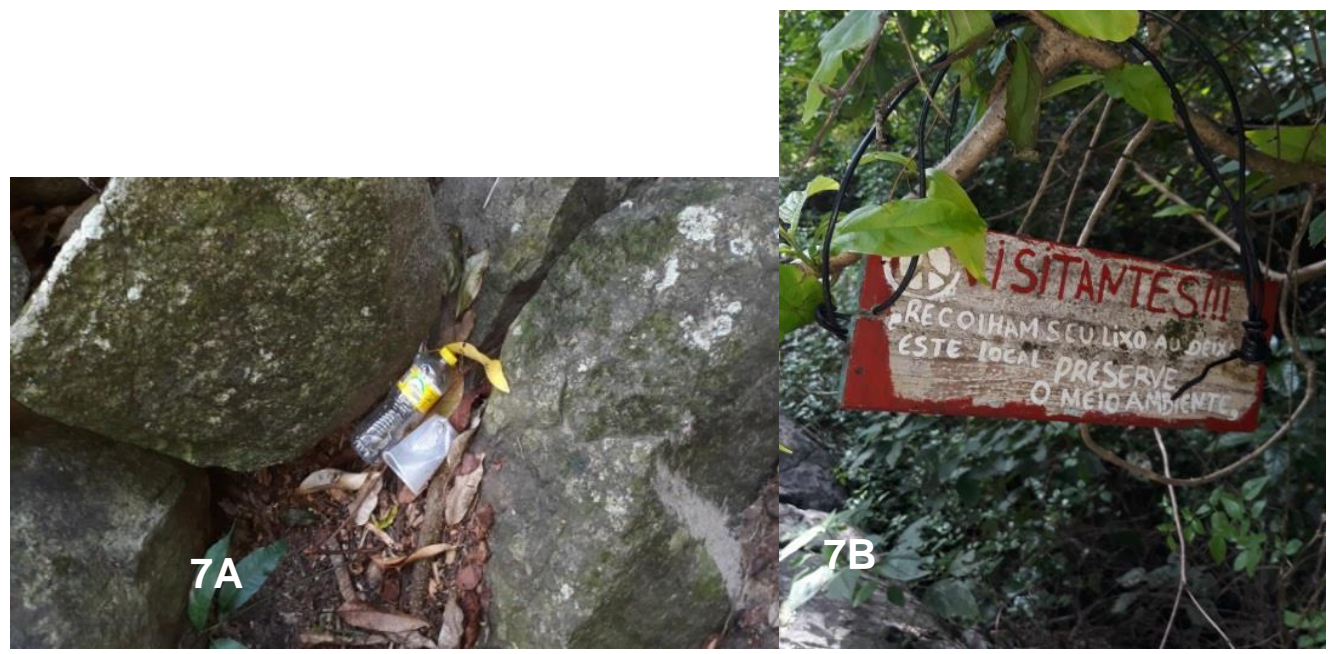

Figura 6: (7a) Resíduos dispostos in natura; (7b) Placa de advertência sobre lixo.

Fonte: Elaboração própria dos autores. 
O baixo conhecimento teórico por parte dos guias torna as trilhas um instrumento ineficiente para o desenvolvimento da Educação Ambiental por não haver a construção de discussões críticas quanto à relevância ambiental dos elementos observados e como a sinergia da natureza é influenciada por eles (GIL; BOMFIM, 2017).

Ao se considerar apenas a utilização das próprias trilhas, durante o acompanhamento das visitas guiadas, não houve atenção ao descarte de resíduos ou ações preventivas aos impactos da presença dos usuários de forma extensiva, mas apenas advertências superficiais.

Outro elemento que se destacou, ao avaliar em campo as trilhas, foi o elevado grau de dificuldade entre as trilhas indicadas como as principais pelos guias. O grau de dificuldade para as trilhas do Boaçu e CETREF se destacou pelo elevado desgaste físico que inviabilizou, para um usuário que não esteja em plena capacidade física, uma maior disponibilidade de atenção e reflexão crítica sobre o cenário e as informações apresentadas. As trilhas na área indígenas apresentaram um menor desgaste físico e permitiram ao usuário médio dispor de maior atenção as eventuais informações apresentadas pelos guias.

Este trabalho buscou aprofundar a pesquisa ao questionar a participação do poder público na atuação na EA não formal a partir de entrevistas com a equipe da Secretaria de Turismo de Pacatuba. Assim, foi possível identificar uma enorme fragilidade na continuidade das ações entre gestões diferentes. Até o ano de 2012 havia a Associação de Condutores de Trilhas - ACOTSAP associada à Secretaria de Turismo, no entanto foram suspensas as atividades da associação entre o ano de 2012 até o ano de 2016. Somente no ano de 2017 a gestão municipal teve um olhar mais sensível em relação ao patrimônio ambiental na serra, assim foi criado o Projeto Trilha Limpa, contudo as ações versaram na limpeza de trilhas sem uma ação integrada e crítica em relação ao potencial para a EA do uso das trilhas.

No ano de 2018 houve, por parte do governo municipal de Pacatuba, a criação de um cadastro e capacitação dos guias de forma a reduzir os problemas quanto à qualidade dos serviços prestados. Contudo, houve dificuldade em se aplicar o cronograma para formação continuada de guias assim, atualmente, a Prefeitura de Pacatuba busca apenas manter um controle de acesso às trilhas através de cadastros prévios para uso.

\section{Conclusão}

A Serra de Aratanha têm um grande patrimônio natural, além das atividades disponíveis de convívio com a natureza, assim possui uma demanda de visitantes para as trilhas ecológicas durante todo o decorrer do ano. As trilhas possuem variados níveis de dificuldade e estão divididas entre os distritos e localidades ao longo do município de Pacatuba onde algumas 
trilhas são realizadas em períodos de chuva e outras quando o clima está mais seco (devido o percurso haver cachoeiras, rios e açudes).

Como forma de potencializar a Educação Ambiental Crítica a partir do uso das trilhas é necessário que haja uma mudança de paradigmas consolidados em relação aos objetivos da utilização das trilhas guiadas em Pacatuba, pois no município elas se apresentam em sua maioria como cênicas e de médio a elevado grau de dificuldade de uso. O desenvolvimento de trilhas interpretativas é fundamental para ir além da comunicação de conceitos, mas permitir que o visitante possa se sensibilizar e cooperar na conservação e proteção ao meio ambiente (MENGHINI, 2005 apud REPOLHO, 2018 et al., 2018).

É necessário pensar um novo modelo de trilhas mais curtas e leves, que não acarretem a exaustão do usuário médio, onde haja uma redução do desgaste físico e a possibilidade de uma maior intepretação do meio, fundamental para permitir ao usuário da trilha internalizar todas as informações repassadas pelos condutores.

Por outro lado, atualmente em Pacatuba, a formação de senso crítico pelos usuários, a partir das informações ministradas pelos guias, é prejudicada, pois os usuários não recebem as informações qualificadas para tal. Os condutores apresentam um perfil sócio educacional de formação empírica do conhecimento ministrado durante as trilhas. Essa formação frágil está intimamente ligada ao caráter não profissional quando executada por moradores da região (que é a maior parte dos condutores cadastrados).

Concluímos, diante da pesquisa, que é necessário que o poder público juntamente com a população pacatubana tenham um olhar mais sensível para as trilhas que são realizadas, assim a prefeitura e sociedade civil trabalhando em conjunto poderão evitar o empobrecimento da biodiversidade e ampliar o senso crítico ambiental e, assim, conservar o espaço natural a partir da compreensão do diálogo histórico-social que busca explicar a baixa sensibilidade ambiental dos usuários de trilhas quando utilizadas para Educação Ambiental conservadora.

Como forma de alcançar um cenário mais favorável à aplicação da Educação Ambiental Crítica são necessárias iniciativas como:

- Mapear todas as trilhas ecológicas que existem na serra dentro do município de Pacatuba permitindo a identificação das com maior potencial para EA;

- Instalar placas de sinalização com o intuito de permitir a construção de trilhas autoguiadas;

- Controlar o acesso de visitantes nas trilhas que por suas características exijam maior atenção por riscos aos usuários ou a natureza;

- Aprimorar o cadastro dos condutores e a formação continuada para garantir que sejam transferidas aos usuários as informações de forma 
qualificada e com o viés necessário para produzir uma mudança positiva nos indivíduos;

- Fiscalizar e monitorar todas as principais trilhas com a frequência necessária para analisar a segurança e o grau de impacto nas trilhas e, assim evitar uma deterioração exacerbadas das mesmas;

- Atuar, em decorrência da identificação que o maior problema nas trilhas é a disposição dos resíduos sólidos por moradores e usuários, com ações de limpeza, assim reduzindo a poluição nos percursos, além de capacitações frequentes com condutores e moradores locais viabilizando o processo de conscientização ambiental continuado e crítico, logo reduzindo as ações paliativas.

\section{Agradecimentos}

A Prefeitura Municipal de Pacatuba (CE), representada pelas Secretarias de Turismo e a Autarquia de Meio Ambiente, que permitiram, cordialmente, a utilização de dados e a entrevista de servidores para a obtenção de dados primários.

\section{Referências}

ALMADA, E. D. B.; BERNADES, M. A.; Educação Ambiental através de trilhas no seminário Regina Minorum Anápolis/GO. Revista de Magistro de Filosofia. Ano VIII, №. 17, 2015. Disponível em: <http://catolicadeanapolis. edu.br/revmagistro/wp-content/uploads/2015/10/06 No 17.pdf>. Acesso em: 07 de novembro de 2019 às 20:30.

AVANZI, M. R. Ecopedagogia. In: LAYRARGUES P.P. (coord.). Identidades da Educação Brasileira. Brasília. Ministério do Meio Ambiente. p.35 - 48. 156 p. 2004.

BRASIL. Programa de Recenseamento de Fontes de Abastecimento por Água Subterrânea no Estado do Ceará. Ministério de Minas e Energia. CPRM. Fortaleza - Ceará. 14 p. 1998.

BRASIL. Politica Nacional de Educação Ambiental. Lei Federal ํo 9.795 de 27 de abril 1999.

BRASIL. IBGE. 2017. Disponível em: <https://cidades.ibge.gov.br/brasil/ce/ pacatuba/panorama>. Acesso em: 05 fev. 2018.

CARVALHO, I. C. M. Educação Ambiental Crítica: Nomes e Endereçamentos da Educação. In: LAYRARGUES P.P. (coord.). Identidades da Educação Brasileira. Brasília. Ministério do Meio Ambiente. p.13 - 23. 156 p. 2004. 
CEARÁ. Caderno Regional das Bacias Metropolitanas. Assembleia Legislativa do Ceará. 136 p. 2009.

FREIRE, E. V.; TEIXIERA, C. P. B.; DUARTE, C. R.; GOMES, D. D. M. Análise da Expansão Urbana no Entorno da APA da Serra da Aratanha/CE. Os Desafios da Geografia Física na Fronteira do Conhecimento. Anais do XVII Simpósio Brasileiro de Geografia Física Aplicada. UNICAMP, SP. V1i. 67066717. 2017. Disponível em: < https://ocs.ige.unicamp.br/ojs/sbgfa/ article/view/1864/2209>. Acesso em: 18 nov. 2019 às 14:17. GAMBÁ. Curso Básico de Formação de Condutor de Visitantes. Grupo
Ambientalista da Bahia. 53 p. 2012. Disponível em: $<$ http://www.gamba.org.br/wp-content/uploads/2014/02/Cartilha-de-Curso-B\% C3\%A1sico-de-Forma\%C3\%A7\%C3\%A3o-de-Condutores-de-Visitantes BoaNova-BA.pdf>. Acesso em: 20 nov. 2019 ás 18:22.

GIL, L. P. B.; BOMFIM, A. M. Educação Ambiental crítica através de trilhas ecológicas, é possível?: Reflexões a partir de uma experiência com alunos do curso técnico em meio ambiente do IFRJ Pinheiral. São Luís - MA, Anais da 38ำ Reunião Nacional ANPED. 2017. Disponível em: $<$ http://anais.anped.org.br//sites/default/files/arquivos/trabalho 38anped GT22 1170.pdf>. Acesso em: 01 de julho de 2019 às 13:32.

GUIMARÃES, M. Educação Ambiental Crítica. In: LAYRARGUES P.P. (coord.). Identidades da Educação Brasileira. Brasília. Ministério do Meio Ambiente. p. 25 - 34. 156 p. 2004.

KRUG, A. L.; PEZENTI, M.; FRÓES,E. H. MILANO, M. Z. Planejamento e Implantação de uma Trilha Interpretativa na Mata Atlântica para a Atividade de Educação Ambiental no Instituto Federal Catarinense Campus Rio do Sul. Anais da VIII Mostra Nacional de Iniciação Científica e Tecnologia Interdisciplinar. Campus Santa Rosa do Sul. 2015. Disponível em:< http://eventos.ifc.edu.br/micti/wp-content/uploads/sites/5/2015/10/PLANEJAME NTO-E-IMPLANTA\%C3\%87\%C3\%830-DE-UMA-TRILHA-INTERPRETATIVANA-MATA-ATL\%C3\%82NTICA-PARA-ATIVIDADES-DE-EDUCA\%C3\%87\%C3 \%830-AMBIENTAL-NO-INSTITUTO-FEDERAL-CATARINENSE-CAMPUS-

RIO-DO-SUL.pdf $>$. Acesso em: 11 nov. 2019 às 18:56.

LOUREIRO, C.F.B. Complexidade e dialética: contribuições à práxis política e emancipatória em Educação Ambiental. Educação e Sociedade, V.27, n.94, p.131-152, 2006.

LOUREIRO, C. F. B. Educação Ambiental Transformadora. In: LAYRARGUES P.P. (coord.). Identidades da Educação Brasileira. Brasília. Ministério do Meio Ambiente. p. 65 - 84. 156 p. 2004. 
PADOAN, L. L. F.; JÚNIOR, H. M. Interpretação Ambiental e Trilhas Interpretativas: Elaboração de uma Proposta de Trilhas Interpretativas para a Serra do Catete, Ouro Preto, Minas Gerais. Anais do X Congresso Nacional de Excelência em Gestão. 14p. 2014. Disponível em: < http://www.inovarse. org/sites/default/files/T14 0271.pdf>. Acesso em: 11 nov. 2019.

PAIVA, G.M.C. A Natureza, a Cultura e o Patrimônio como pilares da dinâmica turística de Pacatuba, Ce. Fortaleza - CE. Dissertação Mestrado Profissional em Gestão de Negócios Turísticos do Programa de Pós-Graduação em Geografia do Centro de Ciências e Tecnologia da Universidade Estadual do Ceará. 2015.

PELACANI, B.; MUNIZ, T. S. A.; PEREIRA, C. S. Educação Ambiental crítica e estudos de patrimônio crítico: intersecções e virada para pedagogias decoloniais. Revista Brasileira De Educação Ambiental, v.14, n.2, p.133$151,2019$.

RAMOS, E. C. Educação Ambiental: origem e perspectivas. Educar, Editora UFPR, Curitiba, n.18, p.201-218. 2001.

ROSA, C. D.; PROFICE, C. C. Que tipo de Educação Ambiental e para quem? Fatores associados a atitudes e comportamentos ambientais. Revista Brasileira de Educação Ambiental, v.13, n.4, p.111-125, 2018.

REPOLHO, S.M.; CAMPOS, D.N.S.; ASSIS, D.M.S.; TAVARES-MARTINS, A.C.C.; PONTES, A.N. Percepções ambientais e trilhas ecológicas: comcepções de meio ambiente em escolas do município de Soure, llha de Marajó (PA). Revista Brasileira de Educação Ambiental, v.13, n.2, p,66-84, 2018.

SANTOS, M. C.; FLORES, M. D.; ZANIN, E. M. Trilhas Interpretativas como Instrumento de Interpretação, sensibilização e Educação Ambiental na APAE de Erechin/RS. Vivências: Revista Eletrônica de Extensão da URI, v.7, n. 13, p.189-197, 2011.

SÃO PAULO. Manejo de Trilhas: Um manual para Gestores. Secretaria de Meio Ambiente. Instituto Florestal de São Paulo. Série Registros n. 35 p. 174. 2008.

SÃO PAULO. Manual de Construção de Manutenção de Trilhas. Governo do Estado de São Paulo. Secretaria de Meio Ambiente, 2009. 172 p. Disponível em: <http://arquivos.ambiente.sp.gov.br/fundacaoflorestal/2017/10/ Manualdas Trilhasfinal07-09.pdf>. Acesso em 01 de jul. 2019 às 19:30.

SILVA, M. M.; NETTO, T. A.; AZEVEDO, L. F.; SCARTON, L. P.; HILLING, C. Trilhas Ecológicas como Prática de Educação Ambiental. Revista Eletrônica em Gestão, Educação e Tecnologia Ambiental, v.5, n.5, p.705 - 719, 2012. 